\title{
More Than Idyll Speculation: Utopian Thinking for Planetary Health
}

\author{
Julian W. Fernando ${ }^{1, *(\mathbb{D}}$, Léan V. $\mathrm{O}^{\prime}$ Brien $^{2}{ }^{2}$ Madeline Judge $^{1}$ and Yoshihisa Kashima ${ }^{3}$ \\ 1 Department of Management and Marketing, University of Melbourne, Parkville 3010, Australia; \\ madeline.judge@unimelb.edu.au \\ 2 Centre for Applied Psychology, University of Canberra, Bruce 2617, Australia; lean.o'brien@canberra.edu.au \\ 3 Melbourne School of Psychological Sciences, University of Melbourne, Parkville 3010, Australia; \\ ykashima@unimelb.edu.au \\ * Correspondence: julianwf@unimelb.edu.au
}

Received: 15 December 2018; Accepted: 13 February 2019; Published: 18 February 2019

check for updates

\begin{abstract}
The problems and challenges associated with planetary health are vast and interconnected, and are therefore requiring of research which takes an all-of-society perspective. Following calls for input from behavioural scientists in discussions about planetary health, we here present a review and synthesis of recent research on utopian thinking and lay beliefs about societal change. For some time, utopian theorists have recognised the capacity of ideals for society to motivate social change behaviour, but this has largely been ignored by behavioural scientists. However, recent research has shown that utopian thinking elicits social change behaviour among ordinary people, and that a utopia with pro-environmental content tends to be especially motivating. Furthermore, changes which are seen as increasing levels of warmth and morality in society elicit greater levels of support and motivation to bring about those changes. These findings have implications for how social movements for planetary health can proceed and provide hope for motivating the necessary social change. We present this work in the hope that it can contribute to the furtherance of efforts for the achievement of planetary health.
\end{abstract}

Keywords: utopia; social change; motivation; environment; society

\section{Introduction}

The achievement of planetary health is likely to require significant cultural transformation. Human behaviour, lifestyles, and culture affect important drivers of planetary health like the level of energy consumption and greenhouse gas emissions [1]. Recently, in this journal, Prescott and Logan [2] called for the input of behavioural scientists in discussions about planetary health. Since planetary health entails a variety of interconnected systems and challenges, and is dependent upon creating change across the whole of society, we believe that an important perspective which behavioural science can bring to bear is an understanding of how ordinary people understand societal change; in particular, how ideals for society-utopias - are understood and whether they have motivating effects. Thinking about utopias engages people with complex and holistic notions of society, which can act as goals that people are motivated to achieve and imagined alternatives against which to compare contemporary society and the challenges we currently face.

At present, little is known about people's ideals for society, or the role of utopian thinking in motivating behaviour. Inasmuch as people are motivated to pursue a vision of their ideal society, they may be motivated to change their lifestyle and culture to be more consistent with their utopian vision [3]. If people's utopian visions contain an image of a healthy planet, this may motivate them to engage in environmentally significant behaviours. Alternatively, other popular utopian visions may 
not contain a healthy planet, and thereby represent challenges to action for planetary health. In what follows, we present a review of emerging behavioural scientific research on utopian thinking-whether people engage in it, its content, and whether it tends to elicit motivation for societal change. We also address related research on people's beliefs about how societies change over time. We thereby hope to bring these perspectives to the attention of those engaged in debate, discussion and research about planetary health.

\section{Utopian Thinking: Do People Do It?}

Before we consider whether utopian thinking is a factor in motivating people to achieve planetary health, we need to know if people engage in it in the first place. It has long been documented that the human tendency to imagine ideal societies has animated action for social change. Images of utopia can be found in myths, religious texts, political theories and social movements, in the establishment of intentional communities, and in a wide array of contemporary utopian texts and images [3-7]. While utopian visions are extremely culturally prominent, perhaps utopian thinking is restricted to authors, artists, political theorists, revolutionaries and people who join intentional communities. Equally, given the negative consequences and connotations of some utopian projects, people may be wary of utopian thinking, or consider it to be simply wishful or naïve. Some utopian theorists have argued that utopian thinking is a universal human phenomenon [4]; indeed, Bloch [7] has contended that the utopian impulse is a given - that humankind constantly longs for a better world. Empirical evidence for this has, however, been lacking.

Before considering the empirical evidence for utopian thinking among ordinary people, we should consider what it is that we take utopian thinking to be. Utopias and utopianism have been defined in various ways; however, we take a broad definition of utopia as "an ideal or best possible society which is hoped or wished for" and have used this definition throughout the research reported below. This broad conceptualisation is preferable as it allows us to trace the overall prevalence of utopian thinking among ordinary people (see [8]), and the different motivational effects of various utopias, rather than constraining utopian thinking to, for example, visions which could plausibly be realised.

Returning now to the question of whether people engage in utopian thinking, in a paper published in 2018 [9], we reported the results of a questionnaire to assess the perceived value and prevalence of utopian thinking (utopianism) among ordinary people, as well as the extent to which people think utopian thinking is a bad idea (anti-utopianism). Across three samples of participants from the USA and UK, we found that people reported engaging in utopianism and anti-utopianism, but that levels of utopianism were much higher than those for anti-utopianism (mean values of 4.45-4.64 on a seven-point scale for utopianism, compared to 2.68-3.08 for anti-utopianism). Clearly, ordinary people find utopian thinking to be a useful activity, and something they engage in, but does it motivate action to achieve societal goals?

\section{The Motivational Capacity of Utopian Thinking}

If utopian thinking is going to play a part in achieving planetary health, as Prescott and Logan [2] have suggested it can, it needs to do more than simply provide a temporary imaginative escape. Utopian theorists have suggested that utopianism can have three functions: change (i.e., motivating people to move their current society closer to the ideal), criticism (exposing the faults of the current society in comparison to the ideal), and compensation (providing an imaginative escape from the real world) (e.g., [3], see also [10,11], and [5,12] for similar formulations). Logically, if utopian thinking is to have a role in changing society, the first two of these three functions should be activated. In the 2018 paper referred to above [9], we showed that this is indeed the case: when people were asked to engage in utopian thinking (i.e., to imagine and write about their own utopia), they subsequently reported a greater desire to take action to change their current society. Utopian thinking also activated the criticism function, in the form of reducing people's satisfaction with their current 
society and reducing system-justifying attitudes (see [13]). There was, however, no effect on the compensation function, suggesting no evidence for the escapist function of utopian thinking.

We also showed a potential mechanism for the workings of utopian thinking. Previous research on fantasy realisation [14] has shown that people exhibit more energisation towards their goals when they first think about them and then consider the current state of affairs (rather than the opposite way around). The reasoning behind this is that thinking about where you are now, after thinking about your goal, refocuses your attention on the obstacles to be overcome in achieving that goal, rather than simply allowing you to drift off into imaginations of the desired state. Although we did not find complete support for this mechanism in utopian thinking, we did find that thinking about one's utopia after thinking about the current society decreased social change motivation and increased satisfaction with one's current society. Thus, it would appear that an important aspect of the motivational effects of utopian thinking is the comparison between the utopian and current societies. While it may seem counterintuitive, grounding one's utopian thinking in the current reality facilitates its motivational effects. A similar line of reasoning runs through psychological theories of hope. So-called "pathways thinking" in which a person generates feasible routes (or indeed several alternate routes) to a goal has been conceptualised as a vital component of hope [15].

\section{What Kind of Utopia?}

Having demonstrated the motivational effects of utopian thinking, one may be prompted to ask whether the specific content of that utopia matters. Are people motivated to achieve any utopian vision, or are some more energising than others? With reference to the concerns of planetary health, we may ask more specifically whether a utopia in which a healthy natural environment is a central feature is a) something for which people strive and b) a utopian vision which generates social change motivation and behaviour. While utopian theorists have identified a range of themes in utopian texts (e.g., [16]), contemporary utopian theory has identified ecology (i.e., a Green utopia, characterised by balancing human development and material comfort with a thriving natural environment) and science and technology (i.e., a Sci-Fi utopia, characterised by advanced technology and material abundance) as two predominant modern utopian themes [17-20], and preliminary results from a recent study confirm that these two themes of utopia are indeed very prevalent among ordinary people's utopias [21]. More broadly, these utopias represent more concrete instantiations of two opposing utopian principles of sufficiency (Green) and abundance (Sci-Fi), which entail contrasting perspectives on human-nature relationships $[18,19,22]$.

Before moving on to the potential motivating qualities of these utopias, we should note that although we use the terms "Green" and "Sci-Fi" to describe these utopian themes, we do not wish to suggest that modern technology is absent from the Green utopia; indeed, many modern ecological utopias envision inventive ways of using modern technology to overcome environmental problems $[19,22,23]$. Thus, within the Green utopian tradition, we can distinguish between Arcadian or "Deep Green" utopias, which are more sceptical about the use of science and technology, and modern ecological utopias which are more technophilic. In our Green vs. Sci-Fi distinction, we are therefore comparing the modern ecological utopia and its ideal of sufficiency, with a technocratic Sci-Fi utopia with its ideal of abundance.

In a series of studies, we tested the motivational qualities of these utopian visions by asking participants to imagine a Green or Sci-Fi utopia (As this research is as yet unpublished, readers wishing to view the entire methodology are directed to a pre-print which has been archived at: https:/ / psyarxiv.com/t6ufv/) [24]. The Green utopia was described as using sustainable technologies and preserving habitats for plants and animals, while ensuring that people have enough so that nobody lives in poverty. The Sci-Fi utopia was described as using advanced technology to fulfil human wants and desires and ensure a prosperous lifestyle for citizens. We found that when people were primed with the Green utopia, they were more likely to be motivated to engage in social change activities and donated more to a pro-environmental charity (provided they evaluated the Green utopia positively). 
By contrast, the Sci-Fi utopia elicited no motivation for social change (across a range of measures), even if it was evaluated positively. This is particularly noteworthy since, as noted above, the major underlying distinction between these two utopias is between sufficiency (Green) and abundance (Sci-Fi). Our research suggests that people are attracted to, and motivated to take action to achieve, a world which is characterised by limitations to material comfort and abundance.

In addition, we observed some possibilities as to why the Green utopia was more motivating. Firstly, when presented with the Green utopia, people experienced greater participative efficacy (i.e., the feeling that their actions can "make a difference" in achieving the Green utopia) than when presented with the Sci-Fi utopia (see [25]). Participative efficacy is a concept which is particularly congruent with utopian thinking. Traditionally, efficacy has been conceptualised as a belief about the likelihood of success in achieving a goal, often based on previous experiences of success in achieving similar goals. However, people do not have experience of achieving a utopian society, nor are they likely to have a realistic expectation of seeing it achieved in their lifetime. Participative efficacy suggests that people can be motivated by feelings of making a difference, whether or not the goal is likely to be achieved through their efforts.

One possible explanation for this can be found in research on people's lay theories about how societies change over time. Many people endorse a so-called folk theory of social change, in which as societies move from traditional to modern, they are assumed to become more competent and technologically developed, but less warm and moral [26,27] and perhaps less environmentally healthy [28]. Similar findings have been observed in other studies and across several countries [29]. For example, people tend to evaluate globalization as having a positive effect on competence, but not warmth [30]. The existence of this folk theory suggests that people may assume that we are already headed towards the Sci-Fi utopia, with increasing levels of competence and development. In addition, people are likely to see a Sci-Fi utopia as being achieved through the actions of experts rather than ordinary people. Thus, even if people wish to achieve a Sci-Fi utopia, they may not feel the need, or have the means, to pursue it. In contrast, as the discourse on planetary health suggests, the achievement of a Green utopia would seem to require societies to change their current course, and these results suggest that this is not only something that people are motivated to achieve, but something in which they feel they can participate and make a difference.

A second finding in our studies was that compared to the Sci-Fi utopia, the Green utopia was viewed as entailing a range of positive qualities such as greater interpersonal warmth and positive emotion, while having a similar level of competence. This result locates a Green utopia in a future where progress does not eschew warmth, and suggests a rejection of modern ways of living that promote competence but not warmth. Research on collective futures dovetails with our finding that a Green utopia was both motivating and imbued with warm positive qualities. Bain and colleagues [31] have shown that, across a variety of different specific future scenarios, people are more motivated to support changes to society when those changes are seen as bringing about a society in which people are more caring and moral (i.e., more benevolent). Notably, benevolence was the only factor found to be consistently motivating in this way. Similarly, Kashima and colleagues' $[26,27]$ work on the folk theory of social change showed that, provided people believe that societal trajectories are not irrevocably fixed, they show a clear preference for community-oriented social policy that will ameliorate a perceived decline in societal communality. Research on vegan futures has also shown that these societies were perceived as warmer, and that this predicted support for policies to encourage vegan diets [32].

While the assumption that future societies will be characterised by less warmth and a degraded environment may seem the very opposite of planetary health, these beliefs about negative trajectories of societal change may alert people to what valued qualities are likely to be declining in society and are therefore requiring of human intervention. Thus, it is not only the starting point of a (Green) utopian ideal that is important, but the recognition of systematic ways in which this ideal has not been pursued in the past. When this kind of thinking occurs, people can be motivated to perform behaviours that arrest or reverse societal declines. 


\section{Where to Next?}

At the heart of this review of research on the utopian thinking of ordinary people is the notion that utopian thinking can be a part of driving real social change. We have provided some preliminary evidence that utopian thinking is not mere daydreaming and is related to the motivation to pursue action. Nevertheless, there is still much we do not know about when and how visions of an ideal society are translated into action. A next step in this regard is research connecting utopian thinking with models of concepts like collective action. For example, the Social Identity Model of Collective Action (SIMCA) [33,34] contains several predictors of collective action which could feasibly be examined as they apply to utopian thinking. One such element is whether a given utopian vision contains strong moral content. People are often motivated to pursue (or oppose) issues which they see as (im)moral [35]. Thus, different utopian visions may differ in their capacity to motivate action to the extent that they are based around moral concerns. There are some promising signs in this regard concerning planetary health, since for many people the preservation of the environment is viewed as a moral issue (e.g., [36]). Another important pathway for investigation is the role of emotions in motivating action. Anger has frequently been cited as an emotion which motivates action [37]; however, it is typically a reaction against perceived injustice, and should therefore only be activated by utopian visions that are responses to the perceived immorality of the current society. Alternatively, utopian visions may elicit action via more positive emotional pathways; for example, future research may also address utopian thinking from a hope theory perspective [15].

While there is still much work to be done in understanding the role of utopian thinking in planetary health, we know from this emerging area of research that ordinary people have beliefs about the societies they live in: where they have been, where they are going, and where they want to be. We know that these beliefs can motivate people to change their world for the better, and we are beginning to understand the processes behind the motivational effects of utopian thinking (although, as outlined above, there may be many other variables which may affect this motivational capacity).

The findings discussed here suggest insights for presenting social change messages for planetary health. Framing social change, or policies to increase planetary health in terms of increasing competence and technological capacity, may not generate much motivation from ordinary people because those things are viewed as increasing in society naturally. On the other hand, emphasising change in terms of benevolence or communality may be more motivating because it (a) redresses a perceived decline in positive social qualities and (b) invites citizenship behaviour from ordinary people. We believe that behavioural science research into understanding people's beliefs and attitudes about the societies they live in, how those societies change, and how they should ideally be, is a crucial element in addressing the vast and interconnected challenges of planetary health.

Author Contributions: J.W.F. developed the concept for the manuscript. L.V.O., M.J. and Y.K. all contributed to the conceptualisation of the manuscript and provided comments on the written manuscript. All authors contributed significantly to the research on which the manuscript if based.

Funding: This research received no external funding.

Conflicts of Interest: The authors have no conflicts of interest to declare.

\section{References}

1. Intergovernmental Panel on Climate Change. Climate Change 2014: Synthesis Report. Available online: https:/ / www.ipcc.ch/report/ar5/syr/ (accessed on 18 February 2019).

2. Prescott, S.L.; Logan, A.C. Larger than life: Injecting hope into the planetary health paradigm. Challenges 2018, 9, 13. [CrossRef]

3. Levitas, R. The Concept of Utopia; Philip Allan: London, UK, 1990.

4. Sargent, L.T. The three faces of utopianism revisited. Utop. Stud. 1994, 5, 1-37.

5. Goodwin, B.; Taylor, K. The Politics of Utopia: A Study in Theory and Practice; St Martin's Press: New York, NY, USA, 1982. 
6. Sargisson, L. Utopian Bodies and the Politics of Transgression; Routledge: London, UK, 2000.

7. Bloch, E. The Principle of Hope; Blackwell: Oxford, UK, 1986.

8. Levitas, R. Sociology and utopia. Sociology 1979, 1, 19-33. [CrossRef]

9. Fernando, J.W.; Burden, N.; Ferguson, A.; O’Brien, L.V.; Judge, M.; Kashima, Y. Functions of utopia: How utopian thinking motivates societal engagement. Pers. Soc. Psychol. Bull. 2018, 44, 779-792. [CrossRef] [PubMed]

10. Levitas, R. For utopia: The (limits of the) utopian function in late capitalist society. Crit. Rev. Int. Soc. Polit. Philos. 2000, 3, 25-43. [CrossRef]

11. Levitas, R. Utopia as Method: The Imaginary Reconstruction of Society; Palgrave Macmillan: London, UK, 2013.

12. Moos, R.; Brownstein, R. Environment and Utopia: A Synthesis; Plenum Publishing: New York, NY, USA, 1977.

13. Jost, J.T. A quarter century of system justification theory: Questions, answers, criticisms, and societal applications. Br. J. Soc. Psychol. 2018. [CrossRef]

14. Oettingen, G. Future thought and behaviour change. Eur. Rev. Soc. Psychol. 2012, 23, 1-63. [CrossRef]

15. Snyder, C.R. Hope theory: Rainbows in the mind. Psychol. Inq. 2002, 13, 249-275. [CrossRef]

16. Davis, J.C. Utopia and the Ideal Society: A Study of English Utopian Writing, 1516-1700; Cambridge University Press: New York, NY, USA, 1981.

17. Carey, J. The Faber Book of Utopias; Faber \& Faber: London, UK, 1999.

18. De Geus, M. Ecological Utopias: Envisioning the Sustainable Society; International Books: Utrecht, The Netherlands, 1999.

19. Garforth, L. Green utopias: Beyond apocalypse, progress and pastoral. Utop. Stud. 2005, 16, 393-427.

20. Stableford, B. Ecology and dystopia. In The Cambridge Companion to Utopian Literature; Claeys, G., Ed.; Cambridge University Press: Cambridge, UK, 2010; pp. 259-281.

21. Fernando, J.W.; Burden, N.; O’Brien, L.V.; Judge, M.; Kashima, Y. An analysis of the content of ordinary people's utopian visions across four countries. Unpublished work.

22. Garfoth, L. Green Utopias: Environmental Hope Before and After Nature; Polity Press: Cambridge, UK, 2018.

23. Pepper, D. Tensions and dilemmas of ecotopianism. Environ. Values 2007, 16, 289-312. [CrossRef]

24. Fernando, J.W.; O’Brien, L.V.; Burden, N.; Judge, M.; Kashima, Y. Greens or space invaders: Prominent utopian themes and effects on social change motivation. PsyArXiv. (Preprint). 2019. Available online: https:/ / psyarxiv.com/t6ufv/ (accessed on 18 February 2019).

25. Van Zomeren, M.; Saguy, T.; Schellhaas, F.M.H. Believing in "making a difference" to collective efforts: Participative efficacy beliefs as a unique predictor of collective action. Group Processes Intergroup Relat. 2013, 16, 618-634. [CrossRef]

26. Kashima, Y.; Bain, P.; Haslam, N.; Peters, K.; Laham, S.; Whelan, J.; Bastian, B.; Loughnan, S.; Kaufmann, L.; Fernando, J. Folk theory of social change. Asian J. Soc. Psychol. 2009, 12, 227-246. [CrossRef]

27. Kashima, Y.; Shi, J.; Tsuchiya, L.; Kashima, E.S.; Cheng, S.Y.; Chao, M.M.; Shin, S.H. Globalization and folk theory of social change: How globalization relates to societal perceptions about the past and future. J. Soc. Issues 2011, 67, 696-715. [CrossRef]

28. Fernando, J.W.; Burden, N.J.; Kashima, Y. Possible and ideal societies. Unpublished work.

29. Cheng, S.Y.Y.; Chao, M.M.; Kwong, J.; Peng, S.; Chen, X.; Kashima, Y.; Chiu, C.-Y. The good old days and a better tomorrow: Historical representations and future imaginations of China during the 2008 Olympic games. Asian J. Soc. Psychol. 2010, 13, 118-127. [CrossRef]

30. Yang, D.Y.-J.; Chiu, C.-Y.; Cheng, S.Y.Y.; Kwan, L.Y.-Y.; Tam, K.-P.; Yeh, K.-H. Lay psychology of globalization and its social impact. J. Soc. Issues 2011, 67, 677-695. [CrossRef]

31. Bain, P.G.; Hornsey, M.J.; Bongiorno, R.; Kashima, Y.; Crimston, D. Collective futures: How projections about the future of society are related to actions and attitudes supporting social change. Pers. Soc. Psychol. Bull. 2013, 39, 523-539. [CrossRef]

32. Judge, M.; Wilson, M.S. Vegetarian utopias: Visions of dietary patterns in future societies and support for social change. Futures 2015, 71, 57-69. [CrossRef]

33. Van Zomeren, M.; Postmes, T.; Spears, R. Toward an integrative social identity model of collective action: A quantitative research synthesis of three socio-psychological perspectives. Psychol. Bull. 2008, 134, 504-535. [CrossRef] 
34. Van Zomeren, M.; Kutlaca, M.; Turner-Zwinkels, F. Integrating who "we" are with what "we" (will not) stand for: A further extension of the Social Identity Model of Collective Action. Eur. Rev. Soc. Psychol. 2018, 29, 122-160. [CrossRef]

35. Skitka, L.J. The psychology of moral conviction. Soc. Personal. Psychol. Compass 2010, 4, 267-281. [CrossRef]

36. Feinberg, M.; Willer, R. The moral roots of environmental attitudes. Psychol. Sci. 2013, 24, 56-62. [CrossRef] [PubMed]

37. Van Zomeren, M.; Spears, R.; Fischer, A.H.; Leach, C.W. Put your money where your mouth is! Explaining collective action tendencies through group-based anger and group efficacy. J. Personal. Soc. Psychol. 2004, 87, 649-664. [CrossRef] [PubMed]

C 2019 by the authors. Licensee MDPI, Basel, Switzerland. This article is an open access article distributed under the terms and conditions of the Creative Commons Attribution (CC BY) license (http:/ / creativecommons.org/licenses/by/4.0/). 